\title{
DESJUDICIALIZAÇÃO DO RECONHECIMENTO DA PARENTALIDADE SOCIOAFETIVA À LUZ DOS PROVIMENTOS N 63 E 83 DO CNJ
}

\section{Michele Matias Malheiro Assad* Samantha Ribeiro Meyer Pflug Marques*}

Resumo: Neste artigo objetiva-se analisar a desjudicialização do reconhecimento da parentalidade socioafetiva à luz dos Provimentos no 63/2017 e 83/2019, ambos do Conselho Nacional de Justiça. Parte-se da premissa que a filiação decorrente de vínculo socioafetivo encontra acolhimento na Constituição Federal vigente. Nesse sentido, a pesquisa mostra-se relevante para a atuação dos registradores civis do Brasil no âmbito do reconhecimento extrajudicial das relações de filiação construídas a partir do afeto. Para compor o estudo utilizou-se o método hipotético-dedutivo e a técnica de pesquisa bibliográfica em livros, revistas, artigos científicos e jurisprudenciais.

Palavras-chave: Afetividade; Reconhecimento de Filiação Socioafetiva; Registro Civil; Provimento do $\mathrm{CNJ}^{\circ}{ }^{\circ}$ 63/2017; Provimento do CNJ nº 83/2019.

\section{DEJUDICIALIZATION OF THE RECOGNITION OF SOCIO-AFFECTIVE PARENTING IN THE LIGHT OF THE PROVISIONS No. 63 AND 83 OF THE CNJ}

Abstract: The present article aims to analyze the deregistration of the recognition of socioaffective parenting in the light of Provisions No. 63/2017 and 83/2019, both from the National Council of Justice. The study is based on the premise that affiliation resulting from a socioaffective bond is accepted in the Federal Constitution. The research is relevant to the performance of civil registrars in Brazil in the context of regularizing the affiliation relationships built from affection. To compose the research, we used the technique of bibliographic research in books, magazines, scientific and jurisprudential articles, organized according to the hypothetical deductive method.

Keywords: Affection; Recognition of Socioaffective Affiliation; Civil Registry; Provision of CNJ No. 63/2017; Provision of CNJ No. 83/2019

\section{INTRODUÇÃO}

A partir da Constituição Federal de 1988, fundada no princípio da dignidade da pessoa humana, um novo tratamento jurídico foi conferido às relações familiares (BRASIL,

\footnotetext{
* Oficial de Registro Civil das Pessoas Naturais e Tabeliã de Notas da Cidade de Pedra Bela, Comarca de Bragança Paulista/SP. Graduada em Direito pela Universidade de Guarulhos/SP. Pós-graduada em Direito Notaria e Registral pela Faculdade Damásio e Pós-graduada em Direito Público e Privado com ênfase em Direito Tributário. Mestranda em Direito pela UNINOVE - Universidade Nove de Julho. E-mail: michelemma@hotmail.com.

* Doutora e Mestre em Direito do Estado pela PUC/SP, Pós-Doutoranda em Direito Constitucional Econômico pela UNIFOR. Professora do Programa de Mestrado e Doutorado em Direito da UNINOVE. Advogada. E-mail: samanthameyer@uol.com.br.
} 
1988). Nesse contexto destaca-se o relevante impacto que o instituto da filiação sofreu a partir da consagração do princípio da igualdade entre os filhos.

Concretizando este princípio, o constituinte põe fim ao tratamento discriminatório e retrógado dado as relações de filiação, proclamando que todos os filhos são iguais e terão os mesmos direitos.

Por meio da vedação de diferenciação de tratamento em relação à origem da filiação, evidencia-se o reconhecimento da possibilidade de verificação da paternidade socioafetiva. Diante disso, a primazia do critério biológico usado para determinação da paternidade começa a ser desconstituída, permitindo o reconhecimento da afetividade como parâmetro de fixação de vínculo paterno-filial.

Ainda que carentes de regulamentação específica, as relações filiais socioafetivas sempre foram uma realidade no Brasil. A doutrina nacional e a jurisprudência, especialmente do Superior Tribunal de Justiça contribuíram significativamente para o desenvolvimento do estudo do tema.

Mas foi em setembro de 2016 que o Supremo Tribunal Federal, a partir do reconhecimento da repercussão geral 622 e no âmbito do Recurso Extraordinário 898.060/SC, admitindo a possibilidade da multiparentalidade, trouxe um expressivo avanço no cenário jurídico quanto ao tratamento do tema (BRASIL, 2016a).

Diante da possibilidade de reconhecimento jurídico da filiação de origem socioafetiva, torna-se necessária a formalização dessa situação no Registro Civil das Pessoas Naturais.

Até pouco tempo, o reconhecimento da filiação socioafetiva era feito somente por intermédio do Poder Judiciário. Os interessados precisavam propor uma ação judicial para obterem o reconhecimento formal do vínculo afetivo. Em virtude disso, uma quantidade significativa de pessoas seguia suas vidas sem jamais conseguir registrar as relações de paternidade socioafetiva consolidadas.

Sob a influência do movimento geral de desburocratização e desjudicialização, começam a surgir no âmbito das Corregedorias-Gerais de Justiça de alguns estados provimentos permitindo o reconhecimento voluntário de filiação socioafetiva, sem interferência judicial, diretamente nas serventias de registro civis.

A existência de diversos provimentos editados por Tribunais de Justiça dos estados da Federação gerava insegurança jurídica, tornando-se necessária uma orientação geral por 
parte da Conselho Nacional de Justiça.

Visando regular de maneira uniforme o procedimento de reconhecimento extrajudicial da parentalidade socioafetiva, a Corregedoria Geral de Justiça do CNJ, em novembro de 2017, edita o Provimento no 63 (BRASIL, 2017), alterado em agosto de 2019 pelo Provimento $n^{\circ} 83$ (BRASIL, 2019), cuja análise constitui objetivo geral do presente artigo.

\section{DO PROVIMENTO No 63 DO CNJ}

Diante da ausência de legislação específica, alguns estados, como Pernambuco, (BRASILa, 2013), Ceará (BRASIL, 2013b), Maranhão (BRASIL, 2013c), Amazonas (BRASIL, 2014), regulamentaram, por meio de provimentos das corregedorias gerais dos respectivos Tribunais de Justiça, o reconhecimento voluntário de paternidade ou maternidade socioafetiva perante os oficiais de registro civis das pessoas naturais.

A existência de diferentes preceitos administrativos sobre o tema fez surgir a necessidade de edição de normas básicas e uniformes para orientar a execução dos serviços extrajudiciais de todos o país.

Nesse sentido, a Corregedoria Nacional de Justiça, no exercício de sua competência regimental, editou o Provimento $\mathrm{n}^{\mathrm{o}}$ 63, de 14 de novembro de 2017, republicado aos 20 de novembro de 2017, que, a partir da Seção II, dos artigos 10 a 15, trata das regras aplicáveis ao procedimento de reconhecimento voluntário extrajudicial da paternidade ou maternidade socioafetiva (BRASIL, 2017).

A possibilidade de reconhecimento voluntário de paternidade biológica perante os oficiais de registro civis contava com regulamentação nacional, desde 17 de fevereiro de 2012, por meio do Provimento do CNJ nº 16 (BRASIL, 2012). Portanto, somente após cinco anos o princípio da isonomia entre os filhos foi concretizado para permitir o reconhecimento espontâneo pelo segmento extrajudicial da filiação socioafetiva, por meio da edição do Provimento do $\mathrm{CNJ} n^{\circ}$ 63/2017.

O Provimento do CNJ n 63 (BRASIL, 2017), na parte introdutória, considerou a ampla aceitação pela doutrina e jurisprudência da paternidade e maternidade socioafetiva, contemplando os princípios da afetividade e da dignidade da pessoa humana como fundamento da filiação civil. 
Considerou também, a possibilidade de o parentesco resultar de outra origem que não a consanguinidade e o reconhecimento dos mesmos direitos e qualificações aos filhos, havidos ou não da relação de casamento ou por adoção, proibida toda designação discriminatória relativa à filiação (arts. 1.539 e 1596 do Código Civil). Além da necessidade de averbação, em registro público, dos atos judiciais ou extrajudiciais que declararem ou reconhecerem a filiação (art. 10, II, do Código Civil) (BRASIL, 2002).

Sopesou ainda, a decisão do Supremo Tribunal Federal no Recurso Extraordinário $\mathrm{n}^{\circ}$ 898.060/ SC, sobre o fato de que a paternidade socioafetiva, declarada ou não em registro público, não impede o reconhecimento do vínculo de filiação concomitante baseado na origem biológica, com efeitos jurídicos próprios (BRASIL, 2016a).

O Provimento $\mathrm{n}^{\circ} 63$ concretizou não só a possibilidade do reconhecimento voluntário extrajudicial da paternidade e maternidade socioafetiva, mas também da multiparentalidade perante as serventias de registro civil, motivos suficientes para torná-lo um dos principais marcos do Direito de Família.

Apesar das inovações trazidas, a norma administrativa sofreu inúmeras críticas, com a apresentação de duas posições sobre o tema, uma defendendo a sua revogação por completo (MP-GO, 2018), a outra, defendendo a manutenção do provimento (IBDFAM, 2018).

O Provimento do $\mathrm{CNJ} \mathrm{n}^{\circ}$ 63/2017 vigorou por quase dois anos sem alterações, permitindo a averbação da paternidade socioafetiva em diversos assentos de nascimento em todo o país.

\section{DO PROVIMENTO No 83 DO CNJ}

Em 14 de agosto de 2019, a Corregedoria Geral de Justiça do CNJ publica o Provimento $n^{o} 83$, que altera o Provimento $n^{o}$ 63, no que se refere ao reconhecimento voluntário extrajudicial da paternidade socioafetiva (BRASIL, 2019).

O novo preceito administrativo considerou, entre outras, a plena aplicação do reconhecimento extrajudicial da parentalidade de caráter socioafetivo para aqueles que possuem dezoito anos ou mais. Além da possibilidade de aplicação desse instituto jurídico aos menores, desde que sejam emancipados, nos termos do parágrafo único do art. $5^{\circ}$, combinado com o art. $1^{\circ}$ do Código Civil (BRASI, 2002).

Considerou ainda, ser recomendável que o Ministério Público seja sempre ouvido nos casos de reconhecimento extrajudicial da parentalidade socioafetiva de menores de 18 
anos.

As principais alterações trazidas pelo Provimento $n^{\circ} 83$ foram o estabelecimento de idade mínima de 12 anos para a pessoa a ser reconhecida, a necessidade de apuração objetiva do vínculo socioafetivo e o encaminhamento obrigatório do procedimento ao Ministério Público. As demais alterações facilitaram a compreensão da redação de alguns artigos do Provimento $n^{\circ} 63$.

De modo geral, a nova regulamentação trouxe modificações e alterações, a partir das sugestões apresentadas à Corregedoria Geral de Justiça, por meio dos Pedidos de Providência $\mathrm{n}^{\mathrm{o}}$ 0006194-84.2016.2.00.0000 (BRASIL, 2018a) e $\mathrm{n}^{\mathrm{o}}$ 0001711.40.2018.2.00.000 (BRASIL, 2018).

\section{ASPECTOS PROCEDIMENTAIS DO RECONHECIMENTO EXTRAJUDICIAL DA PARENTALIDADE SOCIOAFETIVA}

O reconhecimento voluntário extrajudicial da paternidade ou maternidade socioafetiva, requer, como qualquer outro ato praticado perante as Serventias de Registro Civil, a submissão de certos requisitos formais apresentados a seguir.

\subsection{Da qualificação do requerente}

O reconhecimento voluntário de filho é ato jurídico em sentido estrito, personalíssimo, incondicional, formal, unilateral, que requer uma exteriorização de vontade, livre e consciente, por agente capaz de acordo com a lei. Sobre o tema Sílvio Sálvio Venosa (2016, p.285) afirma que "O reconhecimento é espontâneo quando alguém, por meio de ato e manifestação solene e válida, declara que determinada pessoa é seu filho”.

Como leciona Paulo Lôbo (2009, p. 232):

O reconhecimento voluntário é ato livre, pessoal, irrevogável e de eficácia erga omnes. Na classificação dos atos jurídicos, constitui ato jurídico em sentido estrito ou stricto sensu, porque, ao contrário do negócio jurídico, seus efeitos são predeterminados pela lei, não podendo ser estipulados livremente pelas partes. $\mathrm{O}$ ato de reconhecimento, no direito brasileiro atual, além de personalíssimo, apresenta as características da voluntariedade, irrevogabilidade, incondicionalidade.

De tais definições, extrai-se o dever de o oficial registrador qualificar o agente, em sua identidade e capacidade, recepcionar a manifestação de vontade em reconhecer o filho, qualificá-la de acordo com a lei, formalizar o ato e averbar o reconhecimento (SALAROLI, 
2014, p. 146).

O primeiro ato é a verificação minuciosa da identidade do pretenso pai ou mãe socioafetivo, por meio da conferência rigorosa do documento de identificação com foto, cuja cópia deve ser arquivada na serventia (art. 11).

Superada a apreciação da identidade, o segundo ato trata-se da aferição da capacidade de compreensão pelo requerente do ato praticado e dos seus reflexos jurídicos. Esclarece Mario De Carvalho Camargo Neto e Marcelo Salaroli (2014, p. 146): “o registrador deve verificar a capacidade natural do agente, qual seja, sua capacidade de compreensão do ato praticado e suas consequências".

O terceiro, busca analisar se o requerente atende aos requisitos previstos nos parágrafos $2^{\circ}, 3^{\circ}$ e $4^{\circ}$ do artigo 10 do Provimento $n^{\circ} 63$, quais sejam: a) pretenso pai ou mãe socioafetivo deve ser maior de dezoito anos de idade, a despeito do estado civil; b) não pode ser irmão ou ascendente do reconhecido, e por fim; c) ser pelo menos 16 anos de idade mais velho que o filho reconhecido (BRASIL, 2017).

Ressalte-se que as três regras acima aplicadas ao reconhecimento extrajudicial de reconhecimento socioafetivo são também exigidas na adoção (art. $42,{ }^{\circ} 1$ e $3^{\circ}$ do ECA) ${ }^{1}$, embora os institutos não se confundam, isso porque, entre outras diferenças, na adoção há destituição do poder familiar, o que não ocorre na multiparentalidade que amplia esse poder.

Em derradeiro, cumpre observar que o pretenso pai ou mãe socioafetivo deve requerer pessoalmente, perante o Oficial de Registro Civil, o reconhecimento voluntário da parentalidade socioafetiva. Desta feita, resta inviabilizada a utilização de procuração, tampouco o envio do termo próprio assinado, ainda que com firma reconhecia, pelo correio.

Nesse aspecto, pontuou o Min. João Otávio de Noronha:

Ressalte-se que, em sendo voluntário o reconhecimento da paternidade socioafetiva, ela somente pode ser requerida, extrajudicialmente, pelo pretenso pai, de forma pessoal, em vida ou post mortem, em analogia ao art. 42, § $6^{\circ}$ do Estatuto da Criança e do Adolescente e ao art. 1609, inciso III, do Código Civil. Afasta-se, portanto, a possibilidade de que o reconhecimento da paternidade socioafetiva se dê por meio de procuração (BRASIL, 2015a).

\subsection{Do filho a ser reconhecido}

1 Art. 42. Podem adotar os maiores de 18 (dezoito) anos, independentemente do estado civil. (Redação dada pela Lei $n^{\circ} 12.010$, de 2009) Vigência . $\S 1^{\circ}$ Não podem adotar os ascendentes e os irmãos do adotando. $\S 3^{\circ} \mathrm{O}$ adotante há de ser, pelo menos, dezesseis anos mais velho do que o adotando (BRASIL, 2009). 
A redação original do caput do artigo 10 não previa qualquer limitação de idade ao reconhecimento do filho socioafetivo. Nesse ponto, surgiram críticas vez que a construção de laços de afetividade demanda um período de convivência familiar.

A ausência de restrição de idade foi criticada por supostamente facilitar "adoções à brasileira" e burla ao Cadastro Nacional de Adoção, especialmente, em relação às crianças recém-nascidas. Nas palavras do Corregedor Geral de Justiça e Ministro do Superior Tribunal de Justiça João Otávio de Noronha, manifestando-se sobre o pedido de providências formulado pelo Instituto Brasileiro de Direito de Família:

O reconhecimento da paternidade socioafetiva sem que sejam atendidos certos requisitos formais também pode abrir a possibilidade de que se regularizasse fraudes, sequestros, comércio de crianças ("adoção pronta", em especial de crianças de tenra idade), além de concretizar burla ao cadastro nacional de adoção (BRASIL, 2015a).

Inclusive observou-se a propositura de procedimento administrativo disciplinar em face de oficial de registro civil, perante a $2^{\circ}$ Vara de Registros Públicos do Tribunal de Justiça de São Paulo, em virtude da realização de reconhecimento de filiações socioafetivas, no âmbito extrajudicial, de crianças com poucos dias de vida (BRASIL, 2021).

Em decorrência da insegurança jurídica causada pela abrangência da norma, o CNJ dá nova redação ao artigo 10 restringindo a aplicação do instituto aos filhos socioafetivos com idade acima de 12 anos (BRASIL, 2019, art. $1^{\circ}$, inciso I).

A idade do filho a ser reconhecido é o critério usado para determinar o reconhecimento da filiação socioafetiva pela via extrajudicial (acima de 12 anos) ou judicial (abaixo de 12 anos).

Para comprovar a idade, realiza-se simples cálculo aritmético a partir da certidão de nascimento apresentada pelo requerente.

\subsection{Do consentimento do filho}

A redação originária do parágrafo $4^{\circ}$, do artigo 11 , do Provimento $\mathrm{n}^{\circ} 63$ exigia o consentimento se o filho fosse maior de doze anos, pois presume-se que com essa idade a criança já tenha condições de exprimir sua vontade.

Visando ajustar o referido parágrafo com a nova sistemática, a redação atual exige o consentimento do filho menor de dezoito anos (BRASIL, 2019, art. º $^{\circ}$, inciso III). 
Cabe pontuar que permanece inalterada a norma que dispõe sobre a necessidade da coleta pessoal deste consentimento em termo próprio pelo oficial de registro civil ou escrevente autorizado (BRASIL, art. $11, \S 5^{\circ}$ ), bem como a regra que determina o encaminhamento do procedimento ao juiz competente nos termos da legislação local, na falta ou na impossibilidade de manifestação válida do filho, quando exigido (BRASIL, 2017, art. $\left.11, \S 6^{\circ}\right)$.

\title{
4.4 Da anuência dos pais
}

Resta intacta a previsão do parágrafo $3^{\circ}$ do artigo 11 do Provimento $n^{\circ} 63$ que impõe a anuência expressa dos pais biológicos, caso o filho seja menor (idade entre 12 e 18 anos) (BRASIL, 2017). Ou seja, se a criança tiver pai e mãe biológicos no registro, o reconhecimento extrajudicial da filiação socioafetiva poderá ser feito desde que ambos concordem.

Oportuno dizer que no caso de reconhecido maior de idade ou emancipado, a aceitação expressa dos pais registrais, embora não seja obrigatória, se colhida poderá ser utilizada como documento comprobatório do vínculo afetivo (ARPEN, s.d).

Questão relevante diz respeito a necessidade da coleta da manifestação dos pais, em termo próprio, pessoalmente pelo registrador (BRASIL, 2017, art. 11, $\S 5^{\circ}$ ). Essa determinação inviabiliza a utilização de instrumento público ou particular com firma reconhecida no qual conste expressamente a anuência, ou ainda, de procuração.

Sobre o tema Carlos Magno (2017, n.p) observa que:

\begin{abstract}
Entendemos que essa determinação, além de desarrazoada, é inconstitucional, haja vista que estabelece tratamento discriminatório no reconhecimento da filiação a depender de sua origem, se biológica ou socioafetiva, uma vez que o Provimento 16/2012 do CNJ, que dispõe sobre reconhecimento extrajudicial da paternidade biológica, não exige que a anuência da mãe ou do filho maior seja dada pessoalmente, bastando que seja apresentado documento escrito autêntico.
\end{abstract}

$\mathrm{Na}$ falta da mãe ou do pai do menor, ou da impossibilidade da manifestação válida deles, nos casos exigidos, o caso será apresentado ao juiz competente (BRASIL, 2017, art. 11, $\S 6^{\circ}$ ). Assim, na hipótese de registro de nascimento apenas com a maternidade estabelecida, será colhida apenas a anuência da mãe registral, encaminhando o procedimento ao Juiz.

\subsection{Da forma do ato}


$\mathrm{O}$ anexo VI do Provimento $\mathrm{n}^{\mathrm{o}} 63$ traz um modelo próprio de termo de reconhecimento de filiação socioafetiva a ser utilizado pelos oficiais de registro.

Além do termo próprio, o parágrafo $8^{\circ}$, do artigo 11 , permite utilização de documento público ou particular de disposição de última vontade, que de acordo com Nota Técnica acerca do Provimento CNJ no 63/2017 da Arpen Brasil, pode ser realizado por testamento em qualquer das suas formas ordinárias os especiais previstas no Código Civil, ou ainda por codicilo (ARPEN, 2017).

A propósito, especificamente quanto ao reconhecimento de parentalidade socioafetiva por documento de disposição de última vontade, a hipótese é válida, especialmente, diante da possibilidade do reconhecimento post mortem, ou seja, após a morte do suposto pai afetivo, pela via judicial (BRASIL, 2016b).

\subsection{Do registro civil competente}

O reconhecimento da parentalidade socioafetiva pode ser feita em serventia de registro civil diversa daquela em que foi lavrado o registro de nascimento do filho a ser reconhecido. Essa possibilidade além de ser medida de desburocratização, contribui para ampliar o acesso à justiça, em virtude da capilaridade dos Oficiais de Registros Civis, presentes em todos os municípios brasileiros.

Atualmente, os registradores civis contam com um sistema interligado na rede mundial de computadores (Central de Informações de Registro Civil das Pessoas Naturais CRC), regulamentado pelo Provimento 46 do CNJ (BRASIL, 2015b), que disponibiliza uma ferramenta denominada "E-Protocolo", destinada ao envio de documentos eletrônicos representativos de atos que devem ser cumpridos por outras serventias. De acordo com a Nota Técnica da Arpen/BR sobre o Provimento no 83 do CNJ é possível a utilização do "EProtocolo" para o envio do procedimento de filiação socioafetiva a outra serventia (ARPEN, S.d). 


\subsection{Da ausência de litígio}

O CNJ deixa claro, por meio da regulamentação dada a matéria, que somente o reconhecimento de filiação socioafetiva consensual pode ser processado extrajudicialmente. Assim, em caso de litígio deve ser utilizada a via judicial.

Nesse sentido Ricardo Calderón (2019 n.p) afirma:

[...] Que o intuito do CNJ é justamente deixar com as Serventias de Registros de Pessoas Naturais apenas os casos consensuais e incontroversos, sob o quais não pairem quaisquer dúvidas. Quanto aos casos litigiosos, complexos ou que possam ser objeto de alguma outra intenção dissimulada a ideia é que fiquem mesmo com o Poder Judiciário, que tem maiores condições de tratar destes casos.

De acordo com o artigo 13 do Provimento $n^{\circ}$ 63, em caso de discussão sobre o reconhecimento de paternidade ou procedimento de adoção, o reconhecimento de filiação socioafetiva não pode ser realizado pela Serventia de Registro Civil. O requerente deve declarar o desconhecimento da existência de processo judicial discutindo a filiação no termo próprio para se valer da via extrajudicial (BRASIL, 2017).

\subsection{Da irrevogabilidade do reconhecimento da parentalidade socioafetiva}

Uma das características essenciais do reconhecimento voluntário de filiação é a sua irrevogabilidade. Desta forma, uma vez declarada, a filiação não poderá ser revogada pelo declarante.

Acerca do tema, Flávio Tartuce e José Fernando Simão (2007, p. 310), explicam que “ainda com relação à análise do reconhecimento voluntário, trata-se de ato irrevogável, justamente porque envolve estado de pessoas".

Nesse sentido, o parágrafo $1^{\circ}$ do artigo 10 do Provimento $n^{\circ} 63$ estabelece ser irrevogável o reconhecimento voluntário de paternidade ou maternidade socioafetiva, somente podendo ser desconstituído pela via judicial e a partir da observância de algum vício de consentimento (BRASIL, 2017).

Cumprindo a função de aconselhamento jurídico, nesse ponto, o registrador deve atuar com redobrada cautela, recomenda-se esclarecer ao requerente os efeitos jurídicos de cunho patrimonial e pessoal decorrente do ato de reconhecimento e a impossibilidade de retratação.

\subsection{Da tomada de decisão apoiada}


O parágrafo $7^{\circ}$ do artigo 11 relativo ao Provimento $n^{\circ} 63$ dispõe que, em relação às pessoas com deficiência, devem ser observada as regras da tomada de decisão apoiada constantes no artigo 1.783-A do Código Civil (BRASIL, 2002).

Desta forma, a pessoa com deficiência recorre à pelo menos duas pessoas idôneas de sua confiança para prestar-lhe apoio quando da tomada de decisão pelo reconhecimento extrajudicial da socioafetividade, quer na condição de pai ou mãe reconhecedor ou filho reconhecido, nos termos do artigo $6^{\circ}$ da Lei $n^{\circ} 13.146 / 2015$, referente ao Estatuto da Pessoa com Deficiência (BRASIL, 2015c).

\subsection{Da recusa}

O artigo 12 do Provimento $\mathrm{n}^{\circ} 63$ autoriza o registrador recusar a prática do ato, com encaminhamento do pedido ao juiz competente, nos casos de suspeita de fraude, falsidade, má-fé, vício de vontade, simulação ou dúvida sobre a configuração do estado de posse de filho. Mais uma vez, fica evidenciada a necessidade de atuação extremamente cautelosa por parte do registrador.

\subsection{Da demonstração do vínculo socioafetivo}

A redação original do Provimento $n^{\circ} 63$ silenciava a forma pela qual o registrador civil deveria averiguar a existência do vínculo afetivo.

Em geral, os oficiais de registro civis, mesmo diante da ausência de balizas formais mínimas, atuando de forma prudente, realizavam entrevistas reservadas e de forma separada com as partes envolvidas, buscando meios de comprovação da situação fática objeto de formalização.

$\mathrm{O}$ artigo 10 do Provimento $\mathrm{n}^{\circ} 63$ que passou a vigorar com a alínea "a" estabelece que a paternidade ou maternidade socioafetiva deve ser estável e exteriorizada socialmente. A palavra estável nos remete aquilo que é constante, durável e contínuo, portanto, o regramento prestigia o vínculo de filiação afetivo construído a partir de um período longo de convivência. Além disso, o liame socioafetivo também deve ser exteriorizado socialmente, ou seja, reconhecido por terceiros.

Discorrendo sobre o assunto, Ricardo Calderón (2019) assevera que mutatis mutandis, o que o Provimento parece querer dizer com as expressões "estável" e 
“exteriorizado socialmente" é - nada mais nada menos - o que a doutrina e a jurisprudência já apreciavam para declarar a chamada posse do estado de filiação. Para tanto, sempre foi verificada uma tríade de requisitos: nominativo, tractatio e reputati (CALDERÓN, 2019).

Ao abordar os critérios da posse de estado de filho, o Ministro Relator Luiz Fux, no julgamento realizado pelo Supremo Tribunal Federal referente ao Recurso Extraordinário 898.060 de Santa Catarina, com repercussão geral 622 e que inspirou os Provimentos $n^{\circ} 63$ e 83 do CNJ, ensina que: “Assim, seria considerado filho aquele que utilizasse o nome da família (nominatio), fosse tratado como filho pelo pai (tractatio) e gozasse do reconhecimento da sua condição de descendente pela comunidade (reputatio)” (BRASIL, 2016a).

De acordo com os parágrafos $1^{\circ}$ e $2^{\circ}$ do artigo em comento, o registrador atestará a existência do vínculo afetivo mediante apuração objetiva, por meio da análise de elementos concretos, devendo o requerente demonstrar a afetividade por todos os meios de prova em direito admitidos.

Depreende-se da leitura dos parágrafos acima que o ônus de demonstrar a afetividade cabe ao pretenso pai ou mãe socioafetivo. O regramento trouxe um rol meramente exemplificativo de documentos que provam a presença da relação socioafetiva, são eles: a) apontamento escolar como responsável ou representante do aluno; b) inscrição do pretenso filho em plano de saúde ou órgão de previdência; c) registro oficial de que residem na mesma unidade domiciliar; d) vínculo de conjugalidade - casamento ou união estável - com o ascendente biológico; e) inscrição como dependente do requerente em entidades associativas; f) fotografias em celebrações relevantes; g) declaração de testemunhas com firma reconhecida.

Sensível à complexidade da vida familiar, o regramento dispõe que a ausência destes documentos não impede a averbação do ato, desde que o registrador justifique a impossibilidade e declare por qual meio apurou o vínculo, como, por exemplo, uma entrevista realizada de forma reservada e separada com todos os envolvidos cujas declarações tenham sido reduzidas a termo. A propósito, ao que parece, a necessidade de realização de entrevista está em consonância com a importância do ato que está a se registrar (BRASIL, 2019, art. 10$\left.\mathrm{A}, \S 3^{\circ}\right)$.

Quanto ao tema, Flávio Tartuce cita a possibilidade de provar a relação socioafetiva por escritura pública de reconhecimento da parentalidade socioafetiva (TARTUCE, 2019).

Por fim, o parágrafo $4^{\circ}$, regulamenta uma prática comum na atuação registral, o 
arquivamento de todos os documentos colhidos na verificação do vínculo juntamente com o requerimento.

\title{
4.12 Da atuação do Ministério Público
}

O Provimento $n^{\circ} 63$ sofreu críticas pela ausência de previsão que determinasse atuação do Ministério Público nos procedimentos de reconhecimento de paternidade socioafetiva (MP-GO, 2018). Pautado no princípio da segurança jurídica, o artigo 11 passa vigorar com o acréscimo do parágrafo $9^{\circ}$, que prevê expressamente a participação dos membros do parquet, de forma extrajudicial.

Diante disso, o registrador deve encaminhar o expediente ao Ministério Público para parecer conclusivo. Se favorável, o registrador procederá a averbação do reconhecimento no assento de nascimento do reconhecido, e, caso seja desfavorável, o registrador não praticará o ato, comunicará o ocorrido ao requerente, que deverá se valer da via judicial, e arquivará o procedimento. Se ocorrer dúvida por parte do representante ministerial, encaminha-se o feito ao juízo competente para dirimi-la.

Em virtude da nova sistemática não prever nenhuma exceção à regra de envio ao órgão ministerial, surgem dois entendimentos. $\mathrm{O}$ primeiro, sustenta que todos os procedimentos devem ser encaminhados ao MP, inclusive os referentes ao reconhecido maior de idade, salvo dispensa expressa do órgão ministerial (ARPEN, s.d). O segundo, aduz que no reconhecimento do maior de idade é desnecessária a oitiva do MP.

Sobre o tema, Érica Barbosa e Silva (2019, n.p) argumenta que:

\begin{abstract}
[...] tal exigência deve ser atendida apenas se o reconhecido for menor de 18 (dezoito) anos, pois está expresso na justificativa do Provimento $n^{\circ} 83$ que será plena a aplicação do reconhecimento extrajudicial da parentalidade de caráter socioafetivo para maiores de idade, cravando a diferença entre os procedimentos. Com razão tal diferenciação foi feita, pois o reconhecimento do menor deve ser cercado de cautelas, decorrente da proteção integral (art. 227, CF). Já para o reconhecimento do maior basta que a manifestação de vontade das partes, plenamente capazes para o ato, seja livre e esteja em perfeita sintonia com a legislação vigente, o que deverá ser analisado pelo Registrador. Justamente por isso a oitiva do Ministério Público não será necessária.
\end{abstract}

\subsection{Da multiparentalidade extrajudicial}

A visão clássica sobre a filiação possui o sentido de que o reconhecimento resultaria no estabelecimento de um vínculo de um filho com um pai e uma mãe. Ocorre que, com a 
evolução da sociedade, surgiram novas formas de composição familiar, impondo aos operadores do direito uma leitura mais aberta das relações familiares. Nesse contexto, surge a multiparentalidade ou pluriparentalidade, ou seja, situação em que o filho possui dois pais ou duas mães, concomitantemente, produzindo-se efeitos jurídicos em relação à todos eles.

O Supremo Tribunal Federal, no julgamento ocorrido em em 21 de setembro de 2016 referente ao emblemático Recurso Extraordinário 898.060 de Santa Catarina, com repercussão geral 622, aprovou, sob a Relatoria do Ministro Luiz Fux, a seguinte tese: “A paternidade socioafetiva, declarada ou não em registro público, não impede o reconhecimento do vínculo de filiação concomitante baseado na origem biológica, com os efeitos jurídicos próprios" (BRASIL, 2016a, p.04).

Acompanhando a evolução jurisprudencial, a partir de uma perspectiva de desjudicialização do direito de famílias, o CNJ regulamenta a possibilidade do reconhecimento extrajudicial da multiparentalidade por meio da edição do Provimento $n{ }^{\circ} 63$, alterado pelo Provimento $n^{\circ} 83$.

$\mathrm{O}$ artigo 14 do Provimento $\mathrm{n}^{\mathrm{o}} 63$ foi objeto de muitos questionamentos quanto a sua aplicabilidade. Isso porque sua redação se limitava a dizer simplesmente: "O reconhecimento da paternidade ou maternidade socioafetiva somente poderá ser realizado de forma unilateral e não implicará o registro de mais de dois pais e de duas mães no campo FILIAÇÃo no assento de nascimento" (BRASIL, 2017).

Visando eliminar as incertezas quanto à possibilidade ou não de reconhecimento extrajudicial da multiparentalidade e tornar claro o real sentido do termo "unilateral", o novo preceito normativo acrescentou dois parágrafos ao artigo 14. O primeiro, permite somente a inclusão de um ascendente socioafetivo (pai ou mãe) e o segundo, dispõe que a inclusão de mais de um ascendente socioafetivo deve tramitar necessariamente pela via judicial.

Ricardo Calderón (2019) participou dos debates prévios que permearam a elaboração da nova norma representando o IBDFAM, esclarecendo que:

Em consequência, restou esclarecida com estes novos parágrafos a manutenção da admissão da multiparentalidade unilateral: ou seja, a inclusão de ascendente socioafetivo ao lado de um outro biológico que já preexista, mesmo que da mesma linha (dois pais, por exemplo) (CALDERÓN, 2019, n.p).

No mesmo sentido Érica Barbosa e Silva aduz que:

Questão bastante controvertida, agora enfrentada, é o reconhecimento socioafetivo bilateral, o qual não poderá ser realizado no âmbito extrajudicial, pois está vedada a via administrativa para o reconhecimento múltiplo, com dois pais e duas mães no 
campo filiação (art. $14, \S 1^{\circ}$ ). Assim, o procedimento ficou restrito para incluir apenas um ascendente socioafetivo, seja materno ou paterno (SILVA, 2019, n.p).

A esse respeito, à título ilustrativo, anota-se o seguinte caso hipotético, descrito por Ricardo Calderón:

\begin{abstract}
Caso um filho venha a nascer durante uma relação de casamento dos seus pais; logo, terá mãe e pai biológicos registrados; após alguns 4 anos este casal vem a se divorciar,; passados mais dois anos a mulher estabelece uma relação de conjugalidade com um outro homem, por longos anos; quando da adolescência do filho, este outro homem pode vir a pleitear o seu registro como pai socioafetivo, mediante a comprovação dos requisitos do provimento; nesta hipótese, como será o primeiro ascendente socioafetivo a pedir o registro extrajudicial, terá direito e será atendido; consequentemente, o adolescente restará com dois pais registrados (um biológico e um socioafetivo) e uma mãe (a biológica). Logo, restará configurada a multiparentalidade, visto que o dado filho terá três ascendentes, mas apenas um socioafetivo (SILVA, 2019, n.p).
\end{abstract}

\title{
5. CONCLUSÃO
}

Por longo período o reconhecimento da filiação socioafetiva ficou restrito à esfera judicial. Entretanto, ao acompanhar a evolução jurisprudencial sobre o tema, em um primeiro momento, as Corregedorias Gerais do Tribunal de Justiça de alguns estados tornam possível esse tipo de reconhecimento pela via extrajudicial. Posteriormente, a Corregedoria Geral de Justiça do CNJ, por meio do Provimento n ${ }^{\circ}$ 63, impôs regras básicas e uniformes orientando a execução dos serviços extrajudiciais de todo o país quanto a matéria.

A aplicação prática dessa nova realidade nas serventias de registro civil demonstrou que o Provimento $\mathrm{n}^{\circ} 63$ precisava passar por alguns ajustes, conforme anteviu a doutrina. Em razão disso, quase dois anos depois, confirmando a experiência da desjudicialização, o CNJ edita o Provimento $\mathrm{n}^{\circ} 83$, com vistas a aperfeiçoar o procedimento de reconhecimento da parentalidade socioafetiva e esclarecer alguns pontos divergentes.

A edição dos Provimentos $n^{\circ} 63$ e $n^{\circ}$ 83, representou um grande avanço no tratamento jurídico dado a filiação socioafetiva. pois não só concretizou a possibilidade do reconhecimento de parentalidade socioafetiva, como também da multiparentalidade pela via extrajudicial.

Por derradeiro, o presente trabalho demonstrou que a desjudicialização das questões relacionadas à filiação socioafetiva é um caminho sem volta.

\section{REFERÊNCIAS}


ASSOCIAÇÃO NACIONAL DOS REGISTRADORES DE PESSOAS NATURAIS (ARPEN). Nota Técnica da ARPEN/BR sobre o Provimento $\mathbf{N}^{\circ} 83$ da CNJ. Online. [s.d] [s.l]. Disponível em: https://infographya.com/files/NOTA_TECNICA_ARPEN_BR__PROVIMENTO_83_CNJ-1.pdf. Acesso em: 19 jan. 2021.

\section{ASSOCIAÇÃO NACIONAL DOS REGISTRADORES DE PESSOAS NATURAIS} (ARPEN). Nota Técnica da ARPEN/BR sobre o Provimento $\mathbf{N}^{\circ} 63$ da CNJ. Online. [s.1], 07 dez. 2017. Dispoível em: https://www.portaldori.com.br/wp-content/uploads/2017/12/2NOTA-DE-ESCLARECIMENTO-PROVIMENTO-CNJ-Nº-63.pdf. Acesso em: 28 mar. 2021.

BRASIL. Conselho Nacional de Justiça. Pedido de Providências $\mathbf{N}^{\circ} 0006194$ 84.2016.2.00.0000. Requerente: Instituto dos Advogados de São Paulo. Requerido: Conselho Nacional de justiça. Min. João Otávio de Noronha. Brasília, 2018a. Disponível em: https://cnj.jusbrasil.com.br/jurisprudencia/605804062/pedido-de-providencias-pp61948420162000000/inteiro-teor-605804072. Acesso em: 28 mar. 2021.

\section{BRASIL. Conselho Nacional de Justiça. Pedido de Providências $\mathbf{N}^{\circ}$}

0001711.40.2018.2.00.000. Requerente: Colégio de Coordenadores da Infância e da Juventude dos Tribunais de justiça do Brasil. Requerido: Corregedoria Nacional de justiça. Brasília, 2018b. Disponível em: https://cnj.jusbrasil.com.br/jurisprudencia/756840136/pedido-de-providencias-pp17114020182000000/inteiro-teor-756840315. Acesso em: 18 fev. 2021.

BRASIL. Conselho Nacional de justiça. Pedido de Providências $\mathbf{N}^{\circ}$ 000265377.2015.2.00.0000. Requerente: Instituto Brasileiro de Direito de Família. Requerido: Conselho Nacional de Justiça. Brasília, 2015. Disponível em: https://ibdfam.org.br/assets/img/upload/files/Decisao\%20socioafetividade.pdf. Acesso em: 02 mar. 2021.

BRASIL. Conselho Nacional de Justiça. Provimento $N^{\circ}$ 16/2012. Dispõe sobre a recepção, pelos Oficiais de Registro Civil das Pessoas Naturais, de indicações de supostos pais de pessoas que já se acharem registradas sem paternidade estabelecida, bem como sobre o reconhecimento espontâneo de filhos perante os referidos registradores. Brasília: CNJ, 2012. Disponível em:

https://atos.cnj.jus.br/files//provimento/provimento_16_17022012_26102012172402.pdf. Acesso em: 25 jan. 2021.

BRASIL. Conselho Nacional de Justiça. Provimento $N^{\circ}$ 46/2015. Revoga o Provimento 38 de 27/07/2014 e dispõe sobre a Central de Informações de Registro Civil das Pessoas Naturais- CRC. Brasília: CNJ, 2015b. Disponível em: https://atos.cnj.jus.br/atos/detalhar/2509. Acesso em: 11 mar. 2021.

BRASIL. Conselho Nacional de justiça. Provimento $N^{\circ}$ 63/2017. Institui modelos únicos de certidão de nascimento, de casamento e de óbito, a serem adotadas pelos ofícios de registro civil das pessoas naturais, e dispõe sobre o reconhecimento voluntário e a averbação da paternidade e maternidade socioafetiva no Livro "A" e sobre o registro de nascimento e emissão da respectiva certidão dos filhos havidos por reprodução assistida. Brasília: CNJ, 2017. Disponível em: 
https://atos.cnj.jus.br/files//provimento/provimento_63_14112017_19032018150944.pdf. Acesso em: 12 mar. 2021.

BRASIL. Conselho Nacional de justiça. Provimento $\mathbf{N}^{\circ}$ 83/2019. Altera a Seção II, que trata da Paternidade Socioafetiva, do Provimento n. 63, de 14 de novembro de 2017 da Corregedoria Nacional de Justiça. Brasília: CNJ, 2019. Disponível em: https://atos.cnj.jus.br/files//provimento/provimento_83_14082019_15082019095759.pdf. Acesso em: 25 mar. 2021.

BRASIL. Corregedoria Geral da Justiça do Estado de Pernambuco. Provimento $N^{\circ}$ 009/2013. Dispõe sobre o reconhecimento voluntário de paternidade socioafetiva perante os Oficiais de Registro Civil das Pessoas Naturais do Estado de Pernambuco. Pernambuco: TJPE, $2013 a$. Disponível em: http://www.tjpe.jus.br/documents/10180/149195/PROVIMENTO+092013.doc+02.12.2013.p df/a1415bce-2b42-4ca1-8529-9d4540dbc9db. Acesso em: 22 jan. 2021.

BRASIL. Corregedoria Geral da Justiça do Estado do Amazonas. Provimento $N^{\circ}$ 234/2014. Dispõe sobre o reconhecimento voluntário de paternidade socioafetiva perante os Oficiais de Registro Civil das Pessoas Naturais do Estado do Amazonas, e dá outras providências. Amazonas: TJAM, 2014. Disponível em: https://www.tjam.jus.br/index.php/atos-dacorregedoria/atos/provimentos/2014/1927-provimento-n-234-2014-sobre-o-reconhecimentovoluntario-de-paternidade-socioafetiva-perante-os-oficiais-de-registro-civil/file. Acesso em: 19 jan. 2021.

BRASIL. Corregedoria Geral da Justiça do Estado do Ceará. Provimento No 15/2013. Dispõe sobre o reconhecimento voluntário de paternidade socioafetiva perante os Oficiais de Registro Civil das Pessoas Naturais do Estado do Ceará. Ceará: TJCE, 2013. Disponível em: https://corregedoria.tjce.jus.br/provimento-no-152013/. Acesso em: 12 fev. 2021.

BRASIL. Corregedoria Geral da Justiça do Estado do Maranhão. Provimento $N^{\circ}$ 21/2013. Dispõe sobre o reconhecimento voluntário de paternidade socioafetiva perante os Ofícios de Registro Civil das Pessoas Naturais do Estado do Maranhão, e dá outras providências. Maranhão: TJMA, 2013c.

BRASIL. Lei $\mathbf{N}^{\circ} 13.146$ de 06 de julho de 2015. Institui a Lei Brasileira de Inclusão da Pessoa com Deficiência (Estatuto da Pessoa com Deficiência). Brasília: Diário Oficial da União, 07 de jul 2015c. Disponível em: http://www.planalto.gov.br/CCIVIL_03/_Ato20152018/2015/Lei/L13146.htm.

BRASIL. Lei no 10.406, de 10 de janeiro de 2002. Institui o Código Civil. Diário Oficial da União: seção 1, Brasília, DF, ano 139, n. 8, p. 1-74, 11 jan. 2002.

BRASIL. Lei $\mathbf{n}^{\mathbf{0}}$ 12.010, de 3 de agosto de 2009. Dispõe sobre adoção; altera as Leis nos 8.069, de 13 de julho de 1990 - Estatuto da Criança e do Adolescente, 8.560, de 29 de dezembro de 1992; revoga dispositivos da Lei no 10.406, de 10 de janeiro de 2002 - Código Civil, e da Consolidação das Leis do Trabalho - CLT, aprovada pelo Decreto-Lei no 5.452, de 1o de maio de 1943; e dá outras providências. Brasília: Diário oficial da União, 04 ago. 2009. 
BRASIL. Superior Tribunal de Justiça. Recurso Especial $\mathbf{N}^{\circ}$ 1.500.999-RJ. Direito de Família. Processual Civil. Adoção Póstuma. Socioafetividade. Art. 1593 do Código Civil. Possibilidade Art. $42 \S 6^{\circ}$, do ECA. Rel. Min. Ricardo Villas Bôas Cueva. Data de julgamento: 12 abr. 2016c. Disponível em:

https://stj.jusbrasil.com.br/jurisprudencia/339963282/recurso-especial-resp-1500999-rj-20140066708-3/inteiro-teor-339963296. Acesso em: 10 abr. 2021.

BRASIL. Supremo Tribunal Federal. Recurso Extraordinário $\mathbf{N}^{\circ}$ 898.060/SC. Dispões sobre o direito civil e constitucional. Conflito entre paternidades socioafetiva e biológica. Paradigma do casamento. Superação pela Constituição de 1988. Rel. Min. Luiz Fux. Julgado em 22 set. 2016a. Disponível em:

http://redir.stf.jus.br/paginadorpub/paginador.jsp?docTP=TP\&docID=13431919. Acesso em: 23 mar. 2021.

BRASIL. Constituição (1988). Constituição da República Federativa do Brasil. Brasília, DF: Senado Federal: Centro Gráfico, 1988.

BRASIL. Tribunal de Justiça do Estado de São Paulo. Pedido de Providências $\mathbf{N}^{\circ} \mathbf{1 0 9 5 2 6 0 -}$ 83.2020.8.26.0100. Processo administrativo disciplinar. Filiação socioafetiva reconhecimento - estado de posse de filho. São Paulo: $2^{\circ}$ Vara de Registros Públicos, 04 mar. 2021.

CALDERÓN, Ricardo. Primeiras Impressões sobre o Provimento 83 do CNJ. Online. [s.1]: IBDFAM, 2019. Disponível em:

https://ibdfam.org.br/assets/img/upload/files/FINAL\%20Comentários\%20Provimento\%2083$2019 \% 20 \mathrm{CNJ} \% 20$ (revisado\%2021\%20agosto)\%20-\%20calderon\%20-\%20FINAL\%20\%20com\%20referências.pdf. Acesso em: 18 mar. 2021.

INSTITUTO BRASILEIRO DE DIREITO DE FAMÍLIA (IBDFAM). IBDFAM manifestase pela manutenção do Provimento 63-2017 em sua integralidade. Online. [s.l] 09 mai. 2018. Disponível em: https://ibdfam.org.br/noticias/6621/IBDFAM+manifestase+pela+manutenção+do+Provimento+63-2017+em+sua+integralidade. Acesso em: 12 mar. 2021.

LÔBO, Paulo. Direito Civil- Famílias, 2ª ed., São Paulo: Saraiva, 2009.

MAGNO, Carlos. CNJ cria regras para reconhecimento de filiação socioafetiva. Online. [s.l], Portal ANOREG/BR. Disponível em: https://www.anoreg.org.br/site/2017/12/04/artigocnj-cria-regras-para-reconhecimento-extrajudicial-de-filiacao-socioafetiva-por-carlos-magnoalves-de-souza/. Acesso em: 19 mar. 2021.

MINISTÉRIO PÚBLICO DO ESTADO DE GOIÁS (MP-GO). Filiação socioafetiva: MPGO pede questionamento de provimento da Corregedoria Nacional de Justiça. Online. [s.l], 20 mar. 2018. Disponível em: http://www.mpgo.mp.br/portal/noticia/filiacaosocioafetiva-mp-go-pede-questionamento-de-provimento-da-corregedoria-nacional-dejustica--2\#.YHi0ly35RQJ. Acesso em: 17 fev. 2021. 
SALAROLI, Marcelo; CAMARGO NETO, Mario De Carvalho. Registro Civil de Pessoas Naturais: parte geral e registro de nascimento. v. 1, Col. Cartórios. São Paulo: Saraiva. 2014.

SILVA, Érica Barbosa e. Primeiras impressões sobre o Provimento no 83 do CNJ, sobre filiação socioafetiva. Online. [s.1]: Consultor Jurídico, 23 ago. 2019. Disponível em: https://www.conjur.com.br/2019-ago-23/erica-barbosa-impressoes-provimento-filiacaosocioafetiva. Acesso em: 05 mar. 2021.

TARTUCE, Flávio; SIMÃO, José Fernando. Direito Civil. Família. V. 5. São Paulo: Método, São Paulo, 2007.

TARTUCE, Flávio. O provimento 83/2019 do Conselho Nacional de Justiça e o novo tratamento do reconhecimento extrajudicial da parentalidade socioafetiva. Online [s.1]: Portal Migalhas, 2019. Disponível em: https://www.migalhas.com.br/coluna/familia-esucessoes/309727/o-provimento-83-2019-do-conselho-nacional-de-justica-e-o-novotratamento-do-reconhecimento-extrajudicial-da-parentalidade-socioafetiva. Acesso em: 17 mar. 2021.

VENOSA, Sílvio de Sálvio. Direito Civil- Família. 17ª ed. v. 5, São Paulo: Atlas, 2016. 